\title{
DESIGN OF ELECTRO-MECHANICAL DUAL-ACTING PULLEY CONTINUOUSLY VARIABLE TRANSMISSION
}

\author{
K.B. Tawi ${ }^{1}$, B. Supriyo ${ }^{1}$, S. Ariyono ${ }^{2}$, N.A. Husain ${ }^{1}$, A.R.A. Hamid ${ }^{3}$, M.A. Azlan ${ }^{4}$, \\ I.I. Mazali ${ }^{1 *}$ and M.S.C. Kob ${ }^{1}$ \\ ${ }^{\mathbf{1}}$ Faculty of Mechanical Engineering, Universiti Teknologi Malaysia \\ 81610 Johor Bahru, Johor, Malaysia \\ *Email: izmi86@yahoo.com \\ Phone: +60193096860; Fax: +6075566159, \\ ${ }^{2}$ Politeknik Negeri Semarang \\ 50275 Semarang, Jawa Tengah, Indonesia \\ ${ }^{3}$ Malaysia Marine and Heavy Engineering Sdn. Bhd, \\ MMHE West Yard PLO 3, Jalan Pekeliling, \\ 81700 Pasir Gudang, Johor, Malaysia \\ ${ }^{4}$ Faculty of Mechanical and Manufacturing Engineering, Universiti Tun Hussein Onn \\ Malaysia, 86400 Batu Pahat, Johor, Malaysia
}

\begin{abstract}
Pulley-based continuously variable transmission (CVT) with a metal pushing V-belt is fast becoming the preferred choice for global carmakers due to its potential particularly in terms of fuel efficiency thanks to its continuous and wide ratio range. Nevertheless, the existing CVTs still face the issues of high power consumption from the engine because of the application of an electro-hydro-mechanical (EHM) actuation system for its ratio changing process and clamping force mechanism. To address this issue, researchers from Universiti Teknologi Malaysia have successfully developed the prototype of an electro-mechanical dual-acting pulley continuously variable transmission (EMDAP CVT) for automotive applications. The prototype of EMDAP CVT is developed for a maximum input torque of $160 \mathrm{Nm}$ with the application of a metal pushing V-belt. The results from the testing prove that the prototype can vary its ratio from 2.8 to 0.6 and no continuous power is required to maintain a constant CVT ratio. These results suggest that the prototype is workable and future testing in a real car is possible.
\end{abstract}

Keywords: Continuously variable transmission; electro-mechanical; dual-acting pulley; metal pushing V-belt; automotive.

\section{INTRODUCTION}

There are two types of automotive transmissions in the market: the manual transmission with friction clutch and the automatic transmission with hydraulic clutch. Unfortunately, vehicles that use automatic transmission with a hydraulic clutch usually consume more fuel than those that use manual transmission with a friction clutch [1]. This is because of the nature of the hydraulic system itself, which causes the impeller and turbine in the hydraulic clutch to slip during operation, thus reducing its efficiency and eventually increasing the car's fuel consumption. However, many people still prefer automatic transmission to manual transmission due to the convenience that it provides. Pulley- 
based continuously variable transmission (CVT) with a metal pushing V-belt is a type of automatic transmission that is widely used currently. For example, Nissan is using it for its Nissan March while Honda and Mitsubishi also use it in their Honda Brio and Mitsubishi Mirage respectively [2-4]. Nevertheless, a pulley-based CVT currently used by these carmakers applies an electro-hydro-mechanical (EHM) actuation system to change the CVT ratio and to provide sufficient clamping force on the V-belt $[1,5]$. The EHM actuation system works on hydraulic pressure, thus an appropriate hydraulic pump is required to supply continuous pressure during operation, especially to maintain belt tension to prevent slipping. This is usually done by continuously siphoning some of the power from the vehicle's engine, which is thus an inefficient way of using energy and ultimately leads to increased fuel consumption by the car $[1,5,6]$.

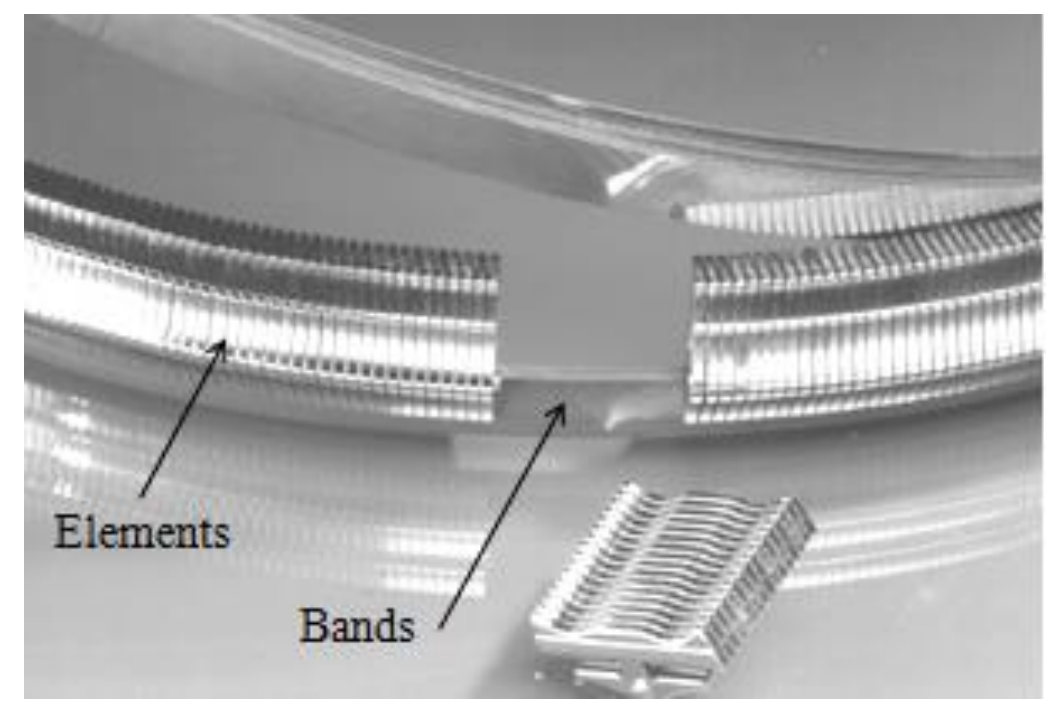

Figure 1. V-belt consisting of two main components: the bands and the elements [10].

In addition, the existing pulley-based CVT with V-belt also uses a single-acting pulley system and unsymmetrical design. With this system, only one half of the pulley sheave is moved axially during the event of changing the CVT ratio. Previous researchers suggest that the single-acting pulley system leads to misalignment of the $\mathrm{V}$ belt during operation [7,8]. The V-belt used in the existing pulley-based CVT consists of two main components, namely the bands and the elements, as shown in Figure 1 [9]. Previous researchers suggest also that V-belt misalignment causes sinusoidal transverse stresses on the V-belt's bands, which could eventually reduce the lifespan of the V-belt $[7,10]$. Not only that, it could also reduce the V-belt's tension during operation, and hence decrease the efficiency of the CVT. Furthermore, V-belt misalignment also causes transverse friction between the V-belt's elements and this could also reduce its lifespan. It is on these notes that the researchers from the Drivetrain Research Group (DRG), Faculty of Mechanical Engineering, Universiti Teknologi Malaysia [11] have studied and evaluated the idea of an electro-mechanical (EM) actuation system for CVT. From this process, a prototype Electro-Mechanical Dual-Acting Pulley CVT (EMDAP CVT) is successfully developed. 


\section{DESIGN METHODS AND CONSIDERATIONS}

The main objective of developing a prototype EMDAP CVT is to prove its workability and functionality. This prototype is designed to handle a maximum input torque of 160 $\mathrm{Nm}$ with an application of a typical metal pushing V-belt (V-belt) produced by Bosch Transmission Technology [12]. On top of that, the EM actuation system developed for EMDAP CVT must be capable of maintaining a constant CVT ratio without using continuous engine power. Other requirements for EMDAP CVT are symmetrical design and a dual-acting pulley mechanism. With symmetrical design, the production cost of the prototype can be reduced due to components commonality, while the dual-acting pulley mechanism can potentially improve the prototype's efficiency and durability.

\section{DESIGN CONCEPT OF EMDAP CVT}

The prototype of EMDAP CVT described in this paper is the fourth version developed by UTM's researchers. Unlike the existing pulley-based CVT with V-belt, it does not use an EHM actuation system. Instead, it uses an EM actuation system to change and to maintain the CVT ratio. Figure 2(a) and Figure 2(b) show the sectional view and the isometric view of the prototype's CAD model respectively. In this actuation system, the indigenously designed power screw mechanisms and two DC servomotors are used to axially move the pulley sheaves of the input (primary) and the output (secondary) pulleys during the process of changing the CVT ratio. Additionally, the prototype also features a dual-acting pulley system, which means that both side pulley sheaves of the primary pulley and the secondary pulley are axially movable for the ratio changing process.

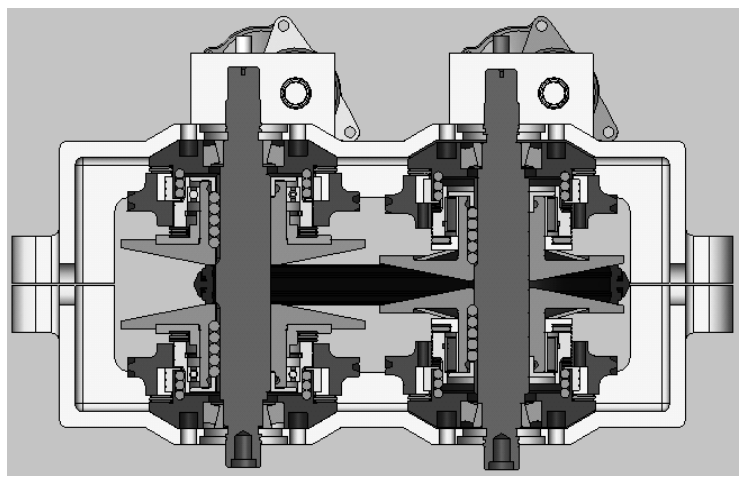

(a)

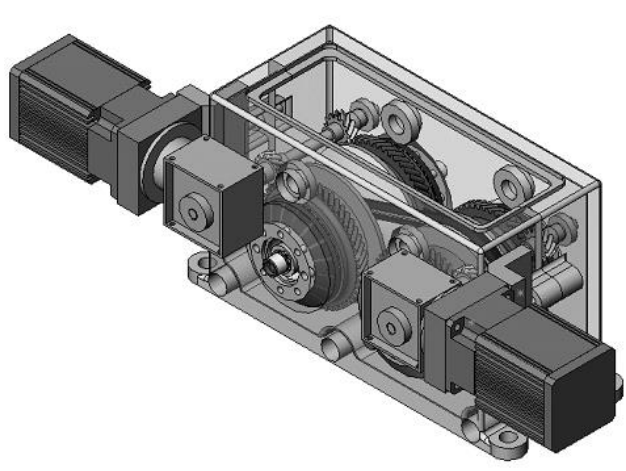

(b)

Figure 2. Sectional view (a) and isometric view (b) of EMDAP CVT's CAD model.

Another notable difference between EMDAP CVT and the existing pulley-based CVT with V-belt is its symmetrical design. Unlike the existing pulley-based CVT with V-belt, EMDAP CVT is designed in such a way that its main components are symmetrical, with the plane of symmetry parallel to the transverse cross-section of both the primary and the secondary shaft mechanisms. The example of this symmetrical characteristic on the primary shaft is shown in Figure 3. Generally, the CVT ratio is changed by varying the radius of the $\mathrm{V}$-belt on the primary and the secondary pulleys accordingly. To vary these radii, the primary and the secondary pulley sheaves need to be moved axially. In the existing pulley-based CVT with V-belt, hydraulic pressure is 
used to perform this procedure. In EMDAP CVT, however, instead of hydraulic pressure, it uses an EM actuation system to perform the ratio change procedure.

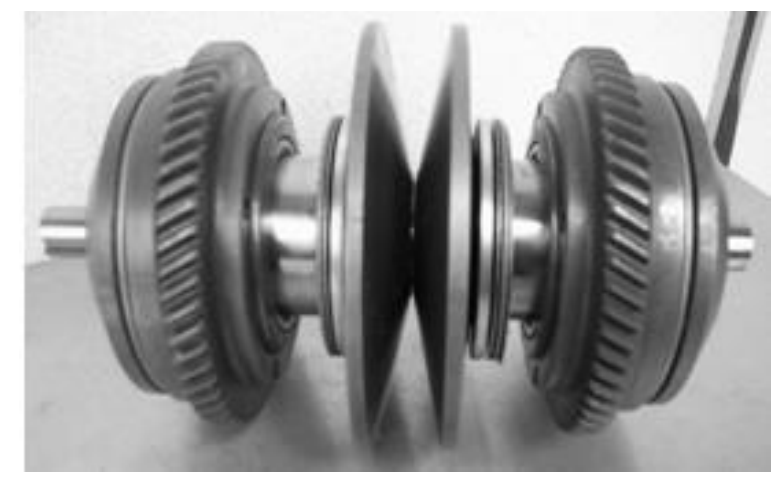

Figure 3. Symmetrical design of EMDAP CVT's primary shaft mechanism.

The EM actuation system in EMDAP CVT mainly consists of a DC servomotor, gear reducer and power screw mechanism. During the procedure of ratio change, the transmission lever triggers the DC servomotor controller, which in turn will instruct the DC servomotors of both the primary pulley and the secondary pulley to turn accordingly as programmed. Then, the DC servomotors via their respective gear reducers turn the power screw mechanism of the primary pulley and the secondary pulley simultaneously. Through the power screw mechanisms, rotational motion is converted into linear motion that exerts equal and opposite axial forces on the pulley sheaves of the primary pulley and the secondary pulley. When changing the ratio, for example from underdrive to overdrive (up-shift), the primary pulley sheaves will move inwards and the secondary pulley sheaves will move outwards, thus increasing and decreasing the V-belt's radius on the primary and secondary pulleys respectively. For changing the ratio from overdrive to underdrive (down-shift), the primary and the secondary pulleys' sheaves will move in the opposite direction to that in the up-shift respectively. With the dualacting pulley system in EMDAP CVT, both the primary pulley and the secondary pulley feature two movable sheaves. During changing of the CVT ratio, both of the movable sheaves are moved axially and simultaneously. This is different from the existing pulley-based CVT with a single-acting pulley system, where only one sheave each is axially moved in the primary pulley and the secondary pulley. Figure 4 shows the movable sheaves of the dual-acting pulley system.

The Belleville springs, which are located at the secondary pulley, cushion up the clamping force and prevent the V-belt from slipping during the process of changing the ratio. The inclusion of Belleville springs also simplifies the controlling strategy for the ratio change procedure [5]. Sufficient clamping force on the V-belt is crucial to ensure minimum slipping of the V-belt so that the torque can be successfully transferred between the primary shaft and the secondary shaft. This clamping force results in the traction force on the V-belt, and the torque that is transferred between the pulleys is the product of the traction force and the radius of the pulleys [6, 13, 14]. Previous researchers suggest that the clamping force required to prevent the V-belt slipping is about $20 \mathrm{kN}$ for 1.6 liter engine applications [10]. 


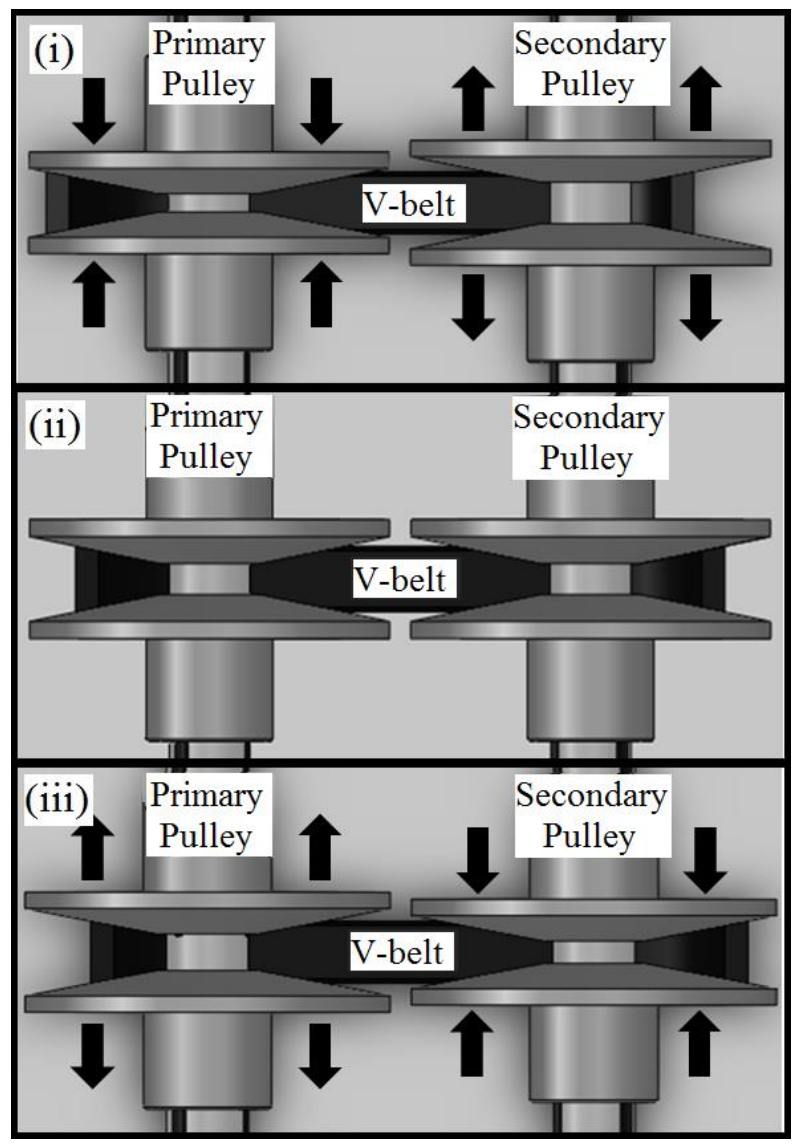

Figure 4. Ratio change with EMDAP CVT's dual-acting pulley system: (i) overdrive ratio; (ii) one-to-one ratio; and (iii) underdrive ratio.

With the EHM actuation system, the existing pulley-based CVT can be designed in such a way that the V-belt can be tensioned automatically during operation. That is why the secondary pulley sheaves piston is usually made smaller in diameter than the primary, because the smaller size diameter is lower down the secondary pulley clamping force relative to the primary. Hence, during operation, the V-belt will be tensioned automatically. The EHM actuation system also makes it possible for the CVT to be designed in such a way that an automatic down-shift is possible when the engine speed decreases, with the inclusion of a compression spring at the secondary pulley. When the engine speed drops, hydraulic pressure from the EHM actuation system will also be reduced since it is generated from the engine's power, and results in decreasing the clamping force on both the primary and secondary pulleys. Thus, the compression spring, with its compression force greater than the reduced clamping force on the pulleys, will clamp the V-belt on the secondary pulley, and so move the pulley axially until the maximum radius of the $\mathrm{V}$-belt on the secondary pulley is reached (maximum underdrive) [15]. Then, this condition remains until the hydraulic pressure builds up again when the engine speed increases.

The prototype of EMDAP CVT, on the other hand, uses an EM actuation system instead of the EHM actuation system. So, in this prototype, the required clamping force on the V-belt is provided by the DC servomotors. The DC servomotors mechanically transmit the required clamping forces to both the primary and secondary pulleys via a gear reducer and power screw mechanism. Once the required clamping force is achieved, the power screw mechanism will maintain it with its self-locking mechanism, 
so no extra power from the engine or the DC servomotors is required to maintain the required clamping force. The same self-locking mechanism is also responsible for maintaining the pulleys' position during the event of constant ratio. Reactions from the clamping forces of the primary and secondary pulleys are taken solely by their respective shaft. These are made possible through the symmetrical design concept. Similar to the present hydraulic actuated CVT designed, both the EMDAP CVT pulleys' sheaves axial forces are transmitted through their respective power screw mechanism and finally stopped by their respective split washer, located equidistant from the center of their respective shafts. Prior to reaching their respective split washers, these axial forces are supported by their respective standard thrust bearings. Thus, the center parts of both the primary and secondary shafts are in tension. At the same time, these shafts are subjected to the tension force by the inextensible V-belt. Hence, only standard ball bearings at both ends of these shafts are enough to support the relevant forces.

\section{PROTOTYPE TESTING}

Testing on EMDAP CVT is carried out with an eddy current dynamometer, and a 1.6 liter engine (1.6L CamPro $\mathrm{S} 4 \mathrm{PH}$ ) is used to provide the input power. The test rig is shown in Figure 5(a) and the prototype EMDAP CVT is shown in Figure 5(b). This testing is carried out from EMDAP CVT's maximum underdrive ratio (2.8) until its maximum overdrive ratio (0.6). The CVT ratio is defined as the ratio of the primary pulley's speed over the secondary pulley's speed. The process to vary this ratio is performed through a PC-based CVT ratio controller. Current used by both the primary and the secondary DC servomotors is measured during the process of changing the CVT ratio and also during the condition of constant CVT ratio.

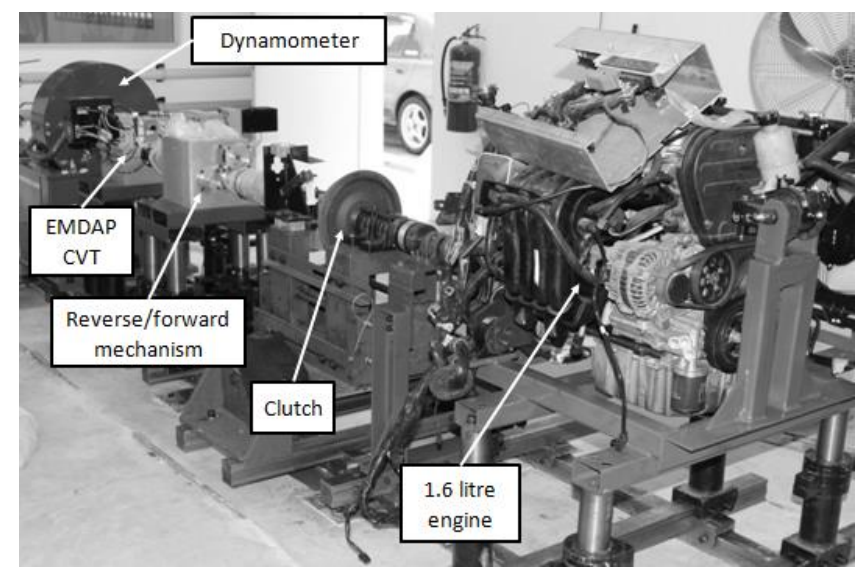

(a)

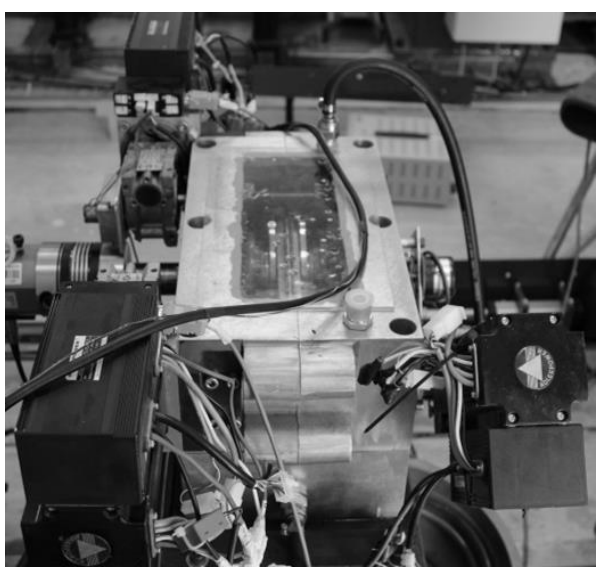

(b)

Figure 5. (a) EMDAP CVT test rig and (b) the prototype of EMDAP CVT.

\section{RESULTS AND DISCUSSION}

The testing proves that the prototype EMDAP CVT is workable with a $1.6 \mathrm{~L}$ engine providing its input torque. Figure 6(a) shows the graph of the CVT ratio changing process from ratio 2.8 to 0.6 . During this process, sufficient torque is provided by both the primary and the secondary DC servomotors to axially move the primary pulley and the secondary pulley simultaneously. The current used during this process is shown in 
Figure 6(b) and Figure 6(c), which represent the current for the primary DC servomotor and the secondary DC servomotor respectively.
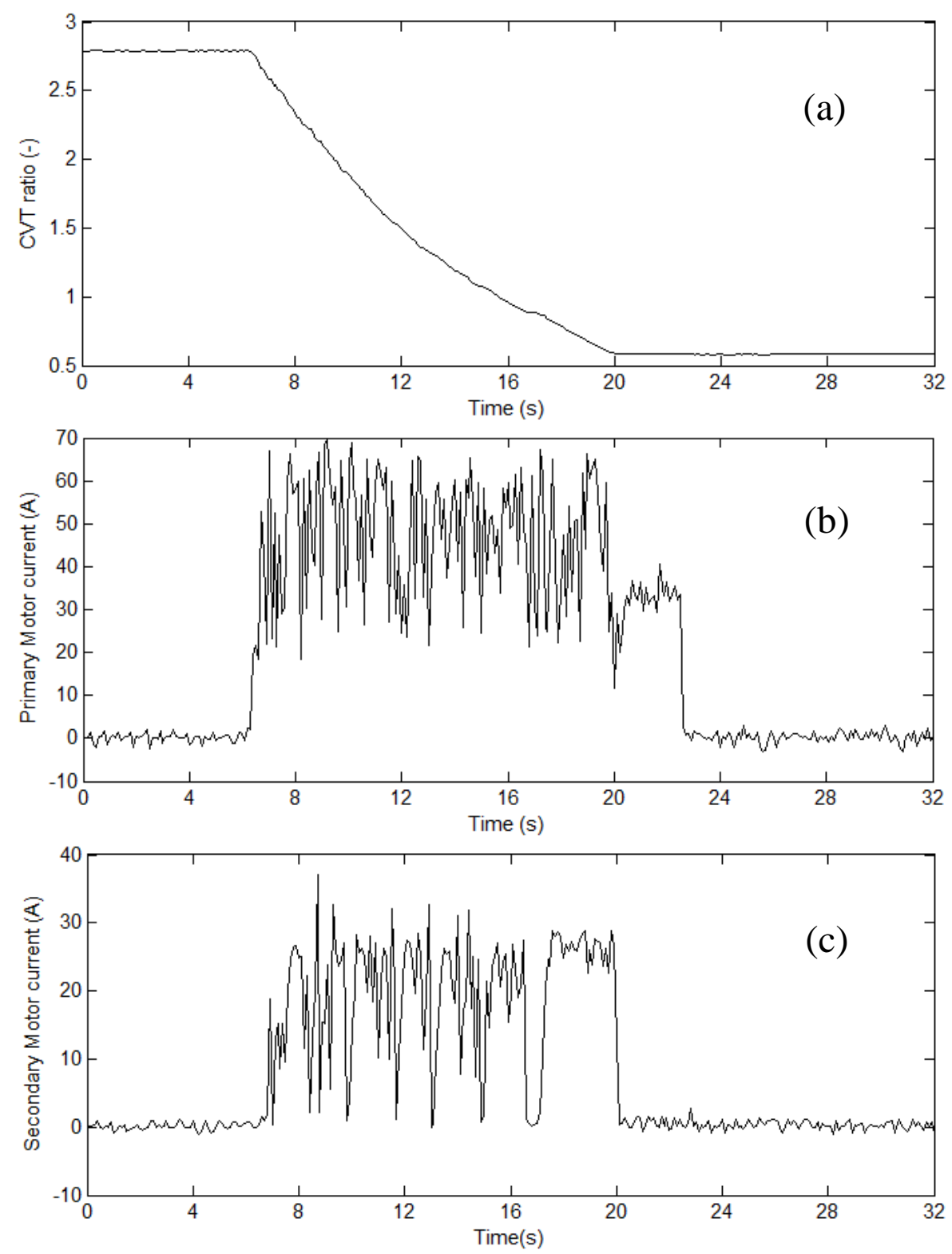

Figure 6. CVT ratio changing process from ratio 2.8 to 0.6 (a), and current used in primary DC servomotor (b), and secondary DC servomotor (c).

Figure 7(a), on the other hand, shows the graph of the CVT ratio changing process from ratio 0.6 to 2.8. Similar to those in Figure 6, Figure 7(b) and Figure 7(c) illustrate the current usage from both the primary and the secondary DC servomotors respectively during the process. These figures prove that no power is required from the engine to maintain the position of the pulleys in the event of constant CVT ratio. The desired CVT ratio is retained through a thread design of the moving power screw mechanism. Unlike the existing pulley-based CVT with V-belt in the market, continuous engine power is required to maintain a constant CVT ratio and this is one of the main reasons that reduces the efficiency of CVT $[1,16]$. As a result, in EMDAP 
CVT, more power from the engine has to be transferred to the wheels for moving the car, potentially improving the fuel economy of the car significantly.
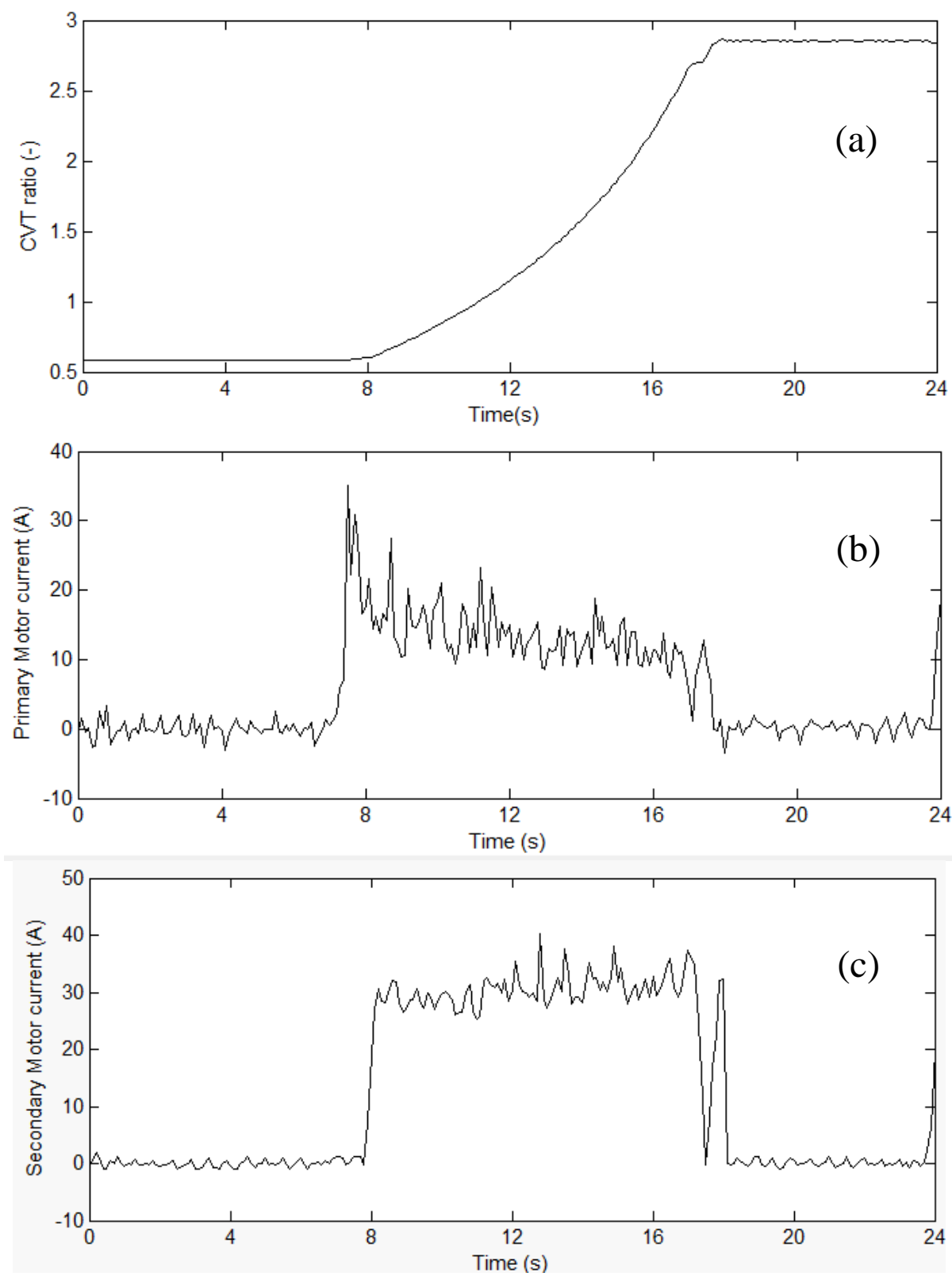

Figure 7. CVT ratio changing process from ratio 0.6 to 2.8 (a), and current used in primary DC servomotor (b), and secondary DC servomotor (c).

In addition, this testing also proves that the dual-acting pulley system of EMDAP CVT is workable. In a single-acting pulley system of the existing CVT, the axial positions of the $\mathrm{V}$-belt on the primary pulley and the secondary pulley are not constant during the changing of the CVT ratio [10]. This is due to the opposite movements of the primary pulley's single movable sheaves and the secondary pulley's single movable sheaves. Hence, the V-belt's misalignment is inevitable in the existing pulley-based CVT with a single-acting pulley system. Studies by some previous researchers suggest that $\mathrm{V}$-belt misalignment causes sinusoidal stresses and transverse forces on the V-belt's band and elements respectively, which reduces the efficiency of 
the CVT while at the same time also decreasing the lifespan of the V-belt $[7,8,16]$. With the dual-acting pulley system of EMDAP CVT, the misalignment of the V-belt is reduced significantly; hence the efficiency of the CVT and the lifespan of the V-belt can be increased. Therefore, the dual-acting pulley system is introduced in EMDAP CVT. This system allows both pulley sheaves to be moved axially during the ratio changing process. With this system, the axial position of the V-belt is maintained while the pulley sheaves are moved axially with the same magnitude in the opposite direction to vary the radius of the V-belt. As a result, the effect of V-belt misalignment is reduced. For validation, Figure 8 shows the geometrical analysis of using the dual-acting pulley system to minimize the effect of V-belt misalignment.

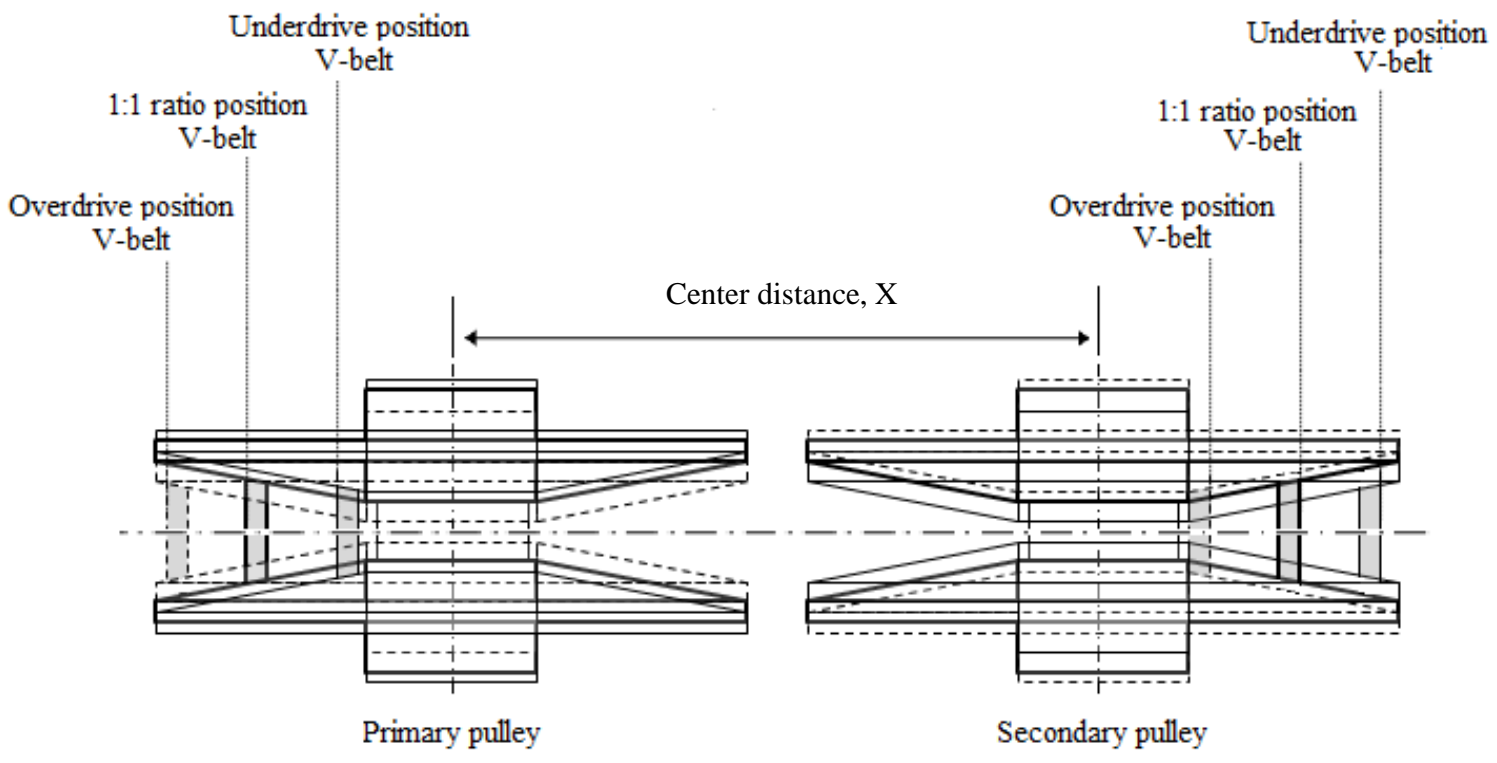

Figure 8. Dual-acting pulley system to maintain the axial position of the V-belt during the CVT ratio changing process, hence minimizing misalignment of the V-belt.

Moreover, the prototype also features a symmetrical design characteristic, which differs from the existing pulley-based CVT that uses an unsymmetrical design. With the symmetrical design, EMDAP CVT has more common components than the existing pulley-based CVT. Thus, the production process of EMDAP CVT's components will be more economical since the same technical drawing can be used for numerous components. Furthermore, due to component commonality, the same production process will also be applicable for numerous components. This potentially reduces the prototype's production cost since the economics of scale of the production process can be realized in a relatively short time.

\section{CONCLUSIONS}

In this paper, the testing of the EMDAP CVT's prototype is performed and it proves that the concept of EMDAP CVT is workable with a $1.6 \mathrm{~L}$ engine providing its input torque. The prototype is capable of varying its ratio from 2.8 (maximum underdrive) to 0.6 (maximum overdrive). During the testing, EMDAP CVT practically requires no continuous power to maintain the desired CVT ratio. For future work, a suitable controller for EMDAP CVT will be introduced to further prepare the prototype for commercialization. Once the controller is completed, the process of integrating the 
prototype into a car will follow, so that real-life testing of the prototype can be performed.

\section{ACKNOWLEDGEMENTS}

The authors would like to thank Universiti Teknologi Malaysia [11] and Malaysian government through the Ministry of Science, Technology and Innovation (MOSTI) for all the supports in term of funding and facilities for this project. The funds used for this project were provided by MOSTI under Technofund with reference number TF0609D131.

\section{REFERENCES}

[1] Kirchner E. Leistungsu bertragung in Fahrzeuggetrieben: Grundlagen Der Auslegung, Entwicklung und Validierung Von Fahrzeuggetrieben und Deren Komponenten. 1 ed: Springer-Verlag; 2007.

[2] Motor N. Nissan Micra/March Tops Six Million Sales Globally; Exciting drivers in over 70 countries since 1982. YOKOHAMA, Japan: Nissan Global; 2011.

[3] Automobile H. Honda Brio makes world premiere in Thailand. Honda Automobile (Thailand) Co., Ltd. (HATC); 2011.

[4] Motor M. 2014 Mitsubishi Mirage: Fun to drive and best in class fuel economy makes mirage a small car for a big city life. Mitsubishi Motor 2013.

[5] Supriyo B, Tawi KB, Jamaluddin H. Experimental study of an electromechanical CVT ratio controller. International Journal of Automotive Technology. 2013;14:313-23.

[6] Sluis Fvd, Noll Evd, Leeuw Hd. Key Technologies of the Pushbelt CVT - Status and New Developments. International Journal of Automotive Engineering. 2013;4:1-8.

[7] Robertson AJ, Tawi KB. Misalignment equation for the Van Doorne metal pushing V-belt continuously variable transmission. Proceedings of the Institution of Mechanical Engineers, Part D: Journal of Automobile Engineering. 1997;211:121-8.

[8] Zang F. Study of the electro-hydraulic control system for CVT metal belt axialmisalignment. International Conference on Mechatronics and Automation. 2009; 1531-5.

[9] van der Laan M, van Drogen M. Improving push belt CVT efficiency by clamping force control strategies based on variator slip measurement. TVT 2005 Cong. 2005;2005:8-13.

[10] Tawi K. Investigation of belt misalignment effects on metal pushing v-belt continuously variable transmission: Cranfield University; 1997.

[11] Duwig C, Stankovic D, Fuchs L, Li G, Gutmark E. Experimental and numerical study of flameless combustion in a model gas turbine combustor. Combustion Science and Technology. 2007;180:279-95.

[12] Bosch. Bosch Transmission Technology Bosch.

[13] Nishizawa H, Yamaguchi H, Suzuki H, Osawa M, Iwatuki K, Oshiumi Y. Friction characteristics analysis for clamping force setup in metal V-belt type CVT. SAE Technical Paper No. 2005-01-1462; 2005. 
[14] Tarutani I, Tani H, Nagasawa Y. Analysis of the power transmission characteristics of a metal v-belt type CVT. R\&D Review of Toyota CRDL. 2005;25:56-9.

[15] Micklem JD, Longmore DK, Burrows CR. Modelling of the steel pushing V-belt continuously variable transmission. Proceedings of the Institution of Mechanical Engineers, Part C: Journal of Mechanical Engineering Science. 1994;208:13-27.

[16] Akehurst S, Vaughan ND, Parker DA, Simner D. Modelling of loss mechanisms in a pushing metal V-belt continuously variable transmission: Part 2: Pulley deflection losses and total torque loss validation. Proceedings of the Institution of Mechanical Engineers, Part D: Journal of Automobile Engineering. 2004;218:1283-93. 